\title{
Nonintubated Thoracic Surgery
}

Editors

VINCENZO AMBROGI

TOMMASO CLAUDIO MINEO

THORACIC

SURGERY CLINICS

www.thoracic.theclinics.com

Consulting Editor

M. BLAIR MARSHALL

February 2020 - Volume 30 - Number 1 